\title{
Analysis of Apple Flavours: The Use of Volatile Organic Compounds to Address Cultivar Differences and the Correlation between Consumer Appreciation and Aroma Profiling
}

\author{
Gareth Roberts ${ }^{1}$ and Natasha D. Spadafora $\mathbb{i D}^{2}$ \\ ${ }^{1}$ Markes International Ltd., Gwaun Elai Medi-Science Campus, Llantrisant, RCT, Ynysmaerdy CF72 8XL, UK \\ ${ }^{2}$ School of Biosciences, Cardiff University, Sir Martin Evans Building, Museum Avenue, Cardiff CF10 3AX, UK \\ Correspondence should be addressed to Natasha D. Spadafora; spadaforan@cardiff.ac.uk
}

Received 13 June 2019; Accepted 9 June 2020; Published 27 June 2020

Academic Editor: Juan Luis Valenzuela

Copyright (C) 2020 Gareth Roberts and Natasha D. Spadafora. This is an open access article distributed under the Creative Commons Attribution License, which permits unrestricted use, distribution, and reproduction in any medium, provided the original work is properly cited.

\begin{abstract}
In the selection of apple (Malus domestica Borkh) fruits, consumers predominantly use visual and organoleptic responses, such as aroma and texture, as quality/preference markers. Previous studies profiling the sensory properties and aroma profiles of apple varieties have provided a lexicon describing important attributes within the modalities of aroma, texture, and flavour. The range of volatile organic compounds (VOCs) produced by four apple cultivars was assessed by thermal desorption-gas chromatographymass spectrometry (TD-GC-MS). To facilitate automated dynamic headspace extraction of the VOCs from bulk samples, a small multichamber thermal extraction system was used. Forty compounds were detected and putatively identified by mass spectral comparison with NIST libraries. Eight compounds were not previously identified in apples. Permutational multivariate analysis of variance (PerMANOVA) and canonical analysis of principal coordinates (CAP) done on the whole volatile organic compound profiles show separation of the four cultivars. The use of random forest classification enabled the determination of a minimum set of fifteen potential VOC markers that successfully differentiate the cultivars under study. Trends across samples, VOCs, and sensory evaluation are revealed. The association between 4-hexen-1-ol acetate with texture/consistency, and crispiness, and correlation of 2-methylbut-2-en-1-yl acetate with juiciness and acidity is shown for the first time. These sensory correlations indicate that the compounds determined by this experiment could be used as objective markers for the consumer appreciation of fresh apples, enabling the optimum conditions for processing and storage of individual cultivars to be identified without recourse to expensive sensory panels in every case. Such tests could also be used as part of routine quality control by the producer and retailer, reducing costs and eliminating waste due to batches of inferior product.
\end{abstract}

\section{Introduction}

Plants produce a wide variety of volatile metabolites. A small subset of these compounds is sensed by animals and humans, and the volatile profiles are the defining elements of the distinct flavours of individual foods (Goff and Klee [1]). In the selection of apples, consumers predominantly use visual and organoleptic responses such as aroma and texture as quality/preference markers (Ting et al. [2]). Previous studies profiling the sensory properties of apple varieties have provided a lexicon describing important attributes within the modalities of odour, texture, and flavour (incorporating retronasal taste and odour) (Corollaro et al. [3]; Seppa et al. [4]). The analysis of aroma profiles is essential for research into apple cultivars, to select the best cultivars for commercial marketing and for routine quality control. The latter issue is particularly important for postharvest, because conditions during packing, transport, and storage can affect shelf life and the perceived "freshness" of the final product (Daillant-Spinnler et al. [5]; Harker et al. [6]).

Reviews carried out by Yahia [7] and Espino-Díaz et al. [8] report that there are more than 300 VOCs associated with fresh apple flavour/odour, further illustrating the 
challenge consumers and trained sensory panellists face when asked to describe apple flavour. It has, however, also been reported that perceived sensory odour assessed by trained panellists could be predicted from a selection of VOCs at different ratios detected by GC-MS analyses (Aprea et al. [9]). Several studies, applied the use of gas chromatography coupled to olfactometry to identify the most potent odourant volatiles in apples (Young et al. [10], Lopez et al. [11], Fuhrmann and Grosch [12], and Mehinagic et al. [13]). Several esters, including isobutyl acetate; acetic acid, butyl ester; propanoic acid, butyl ester; butanoic acid, butyl ester; acetic acid, hexyl ester, have been reported as principal odourant compounds (POC) in apple aroma [13], while the aldehydes $\mathrm{n}$-hexanal and trans-2-hexenal have been known as green apple-like odours [12].

In this study, VOCs were collected using a small automated microchamber thermal extraction system operating in dynamic headspace mode and thermal desorption-gas chromatography-time-of-flight mass spectroscopy (TD-GCTOF-MS). In particular, thermal desorption-gas chromatography-mass spectrometry (TD-GC-MS) is an effective technique for producing a rapid VOC "fingerprint" from freshly cut fruit without further processing or solvent-based extraction (Amaro et al. [14]). This technique previously used to characterise fruit and vegetables during their shelf life and to distinguish between cultivars (Bell et al. [15]; Spadafora et al. [16]) enables a broad range of VOCs to be identified. A novel approach was the implementation of dynamic headspace extraction of sample using an automated multichamber thermal extraction system. This is a highly efficient approach increasing sample throughput compared to time-consuming consumer and/or trained panel tests. Analysis of VOC profiles using this technique shows excellent discrimination between the four cultivars, providing useful markers to distinguish between apple cultivars evaluated in this study.

By combining information from a descriptive sensory study with the VOCs profiled by TD-GC-MS analysis for each cultivar, specific compounds could be identified having an impact on sensory properties. Such information is important because while sensory analysis is the gold standard in providing sample descriptors based on human perception, descriptive panels are costly and rely on strict selection and specific training before product evaluation (Murray et al. [17]). The development of analytical techniques that could assist in predicting these results is therefore advantageous. The end goal is to help the entire food industry supply chain, from "farm to fork," to objectively select cultivars highly appreciated by consumers in order to increase the repeat consumer market.

\section{Materials and Methods}

2.1. Sample Material. Four commercial apple cultivars (Malus domestica Borkh) (Gala, Smitten, Rubens, and Granny Smith) were obtained from a local supermarket in Cardiff. All apples under study were within the EU Specific Marketing Standard (SMS) for apples (Class I) (Commission Implementing Regulation (EU) No 543/2011) as stated on the label. Standard commercial size was addressed by the maximum diameter $(63 / 73 \mathrm{~mm}$ for Gala, Smitten, and Granny Smith and 53/63 for Rubens). Apples for each cultivar (minimum 30) were washed, deskinned, and decored, and the flesh was cut into pieces approximately $2 \mathrm{~cm} \times 2 \mathrm{~cm} \times 2 \mathrm{~cm}$.

2.2. Consumer Test. The consumer test consisted of a questionnaire presented to a group a pool of consumers recruited to evaluate each cultivar. Participants were interviewed to gather data on age, gender, and apple eating habits. Pools of 6-10 fruits were assayed for each apple cultivar in three replicates. Consumers were asked to bite in apple segments and to rate the aroma/smell, taste/flavour, texture/consistency, crispiness, fruitiness, sweetness, acidity, juiciness, and overall acceptability. Hedonic general labelled magnitude scale (gLMS) was used for the rating (Bartoshuk et al. [18]). This scale assesses the liking of apple in the context of all pleasure/displeasure experiences: $1=$ strongest disliking of any kind experienced; 7 = strongest liking of any kind experienced. A total of 230 consumer data sets were used for the analysis.

\subsection{Volatile Organic Compound Collection and Analysis.} To sample the VOCs, the microchamber thermal extraction system ( $\mu$-CTE -Markes International Ltd.), which contains four $114 \mathrm{~cm}^{3}$ capacity, inert-coated stainless steel, microchambers in one heating block, was used. The microchamber was set at $37^{\circ} \mathrm{C}$ for $15 \mathrm{~min}$ to equilibrate the samples. Then, each microchamber was purged with $50 \mathrm{~mL} / \mathrm{min}$ flow of pure nitrogen for $10 \mathrm{~min}$ allowing the emitted VOCs to be collected onto thermodesorption tubes (Markes international Ltd., C2-CAXX-5314) connected to the outlets.

A Centri ${ }^{\mathrm{TM}}$ (Markes international Ltd) preconcentration system was used to desorb the tubes into the cold trap with the following conditions: desorption for $10 \mathrm{~min}$ at $280^{\circ} \mathrm{C}$ with a trap flow of $40 \mathrm{~mL} / \mathrm{min}$. Desorption of trap was at a rate of $40^{\circ} \mathrm{C} / \mathrm{s}$ to $300^{\circ} \mathrm{C}$ with a split ratio of $3: 1$ into the GC (7890 A, Agilent Technologies, Inc). VOCs were separated over $30 \mathrm{~m}, 0.25 \mathrm{~mm}$ ID, $0.25 \mu \mathrm{m}$ film thickness BP5MS ${ }^{\mathrm{TM}}$ (SGE) column using the following temperature program: $3 \mathrm{~min}$ at $40^{\circ} \mathrm{C}$ initially, $4^{\circ} \mathrm{C} / \mathrm{min}$ to $220^{\circ} \mathrm{C}$, hold for $1 \mathrm{~min}$, followed by $10^{\circ} \mathrm{C}$ to $250^{\circ} \mathrm{C}$, and a final hold of $5 \mathrm{~min}$. The mass spectrometer (5977A, Agilent Technologies, Inc.) was operated at an ion source temperature of $200^{\circ} \mathrm{C}$, and ions were collected in a mass range of 35 to $350 \mathrm{~m} / z$. A retention time standard (C8-C20, Sigma Aldrich) was prepared by injection of $1 \mu \mathrm{L}$ of the standard mixture directly onto a collection tube and analysed.

TargetView $^{\mathrm{TM}}$ GC-MS and ChromSpace ${ }^{\mathrm{TM}}$ software (Markes international Ltd) was used to selectively remove unwanted background noise and to deconvolve analyte peaks, improving the identification of lower-level analytes during subsequent automated comparison against a customised retention-indexed mass spectral library generated from spectra in the NIST/EPA/NIH Mass Spectral Database (NIST 17). Compounds, which were not detected in all replicates, were excluded from further analysis as were 
TABLE 1: List of VOCs detected across all samples and codes used for the statistical analyses.

\begin{tabular}{|c|c|c|c|}
\hline Code & VOC name & Chemical family & Retention index* \\
\hline $\mathrm{C} 1$ & (+)-2-bornanone & Ketone & 1141 \\
\hline $\mathrm{C} 3$ & $\gamma$-Himachalene & Sesquiterpenoid & 1509 \\
\hline $\mathrm{C} 4$ & 1-Butanol & Alcohol & 902 \\
\hline C6 & 1-Butanol, 2-methyl-, acetate & Acetate ester & 884 \\
\hline $\mathrm{C} 9$ & 2,4-Hexadiene, $(E, Z)$ - & Alkene & 1112 \\
\hline $\mathrm{C} 10$ & 2-Hexen-1-ol, acetate, (Z)- & Acetate ester & 1019 \\
\hline $\mathrm{C} 11$ & n-Hexanal & Aldehyde & 854 \\
\hline $\mathrm{C} 13$ & 2-Methylbut-2-en-1-yl acetate & Acetate ester & 926 \\
\hline $\mathrm{C} 14$ & 3-Carene & Terpene & 1008 \\
\hline $\mathrm{C} 16$ & 4-Hexen-1-ol acetate & Acetate ester & 1010 \\
\hline $\mathrm{C} 17$ & Acetic acid & Carboxylic acid & 802 \\
\hline $\mathrm{C} 18$ & Acetic acid, butyl ester & Acetate ester & 822 \\
\hline C19 & Acetic acid, heptyl ester & Acetate ester & 1115 \\
\hline $\mathrm{C} 20$ & Acetic acid, hexyl ester & Acetate ester & 1017 \\
\hline $\mathrm{C} 22$ & Acetic acid, pentyl ester & Acetate ester & 918 \\
\hline $\mathrm{C} 25$ & Butanoic acid, 2-methyl-, 2-methylbutyl ester & Nonacetate ester & 1106 \\
\hline $\mathrm{C} 26$ & Butanoic acid, 2-methyl-, hexyl ester & Nonacetate ester & 1239 \\
\hline $\mathrm{C} 27$ & Butanoic acid, 2-methyl-, pentyl ester & Nonacetate ester & 1141 \\
\hline $\mathrm{C} 28$ & Butanoic acid, 2-methyl-, propyl ester & Nonacetate ester & 949 \\
\hline $\mathrm{C} 29$ & Butanoic acid, 2-methylbutyl ester & Nonacetate ester & 1061 \\
\hline $\mathrm{C} 30$ & Butanoic acid, 2-methylpropyl ester & Nonacetate ester & 959 \\
\hline C31 & Butanoic acid, butyl ester & Nonacetate ester & 999 \\
\hline $\mathrm{C} 32$ & Butanoic acid, hexyl ester & Nonacetate ester & 1194 \\
\hline C33 & Butanoic acid, propyl ester & Nonacetate ester & 904 \\
\hline C34 & Butyl 2-methylbutanoate & Nonacetate ester & 1044 \\
\hline C36 & Camphor & Ketone & 1142 \\
\hline $\mathrm{C} 43$ & Estragole & Benzenoid VOC & 1197 \\
\hline $\mathrm{C} 44$ & Ethyl acetate & Acetate ester & 712 \\
\hline C47 & Hexanoic acid, 2-methylbutyl ester & Nonacetate ester & 1254 \\
\hline $\mathrm{C} 48$ & Hexanoic acid, hexyl ester & Nonacetate ester & 1388 \\
\hline C49 & Hexanoic acid, pentyl ester & Nonacetate ester & 1289 \\
\hline $\mathrm{C} 50$ & Hexanoic acid, propyl ester & Nonacetate ester & 1097 \\
\hline C51 & Hexyl tiglate & Nonacetate ester & 1331 \\
\hline C52 & Isobutyl acetate & Acetate ester & 781 \\
\hline C53 & L-Fenchone & Ketone & 1086 \\
\hline C56 & n-Propyl acetate & Acetate ester & 744 \\
\hline C58 & Propanoic acid, 2-methyl-, hexyl ester & Nonacetate ester & 1151 \\
\hline C59 & Propanoic acid, butyl ester & Nonacetate ester & 913 \\
\hline C60 & Propanoic acid, hexyl ester & Nonacetate ester & 1108 \\
\hline C61 & Propanoic acid, pentyl ester & Nonacetate ester & 1011 \\
\hline
\end{tabular}

$* \mathrm{RI}=$ retention index based on a combination of retention times compared to C8-C20 alkane standards and calculated Kovats indices checked against the NIST library. The compounds in italics were not previously identified in apples.

compounds that were abundant in control. Putative identifications of compounds were based on matches of their mass spectra $(>80 \%)$ and a retention index $(\mathrm{RI} \pm 20)$. Peak areas of the compounds were normalized within samples and were standardised for each analyte.

2.4. Statistical Analysis. VOC data was analysed statistically using $\mathrm{R}$ software version 3.1.3 ( $\mathrm{R}$ core development team, 2015) after normalisation of areas and square root transformation to reduce the weight of large components. Permutational multivariate analysis of variance (PerMANOVA) and canonical analysis of principal coordinates (CAP) were performed (Anderson and Willis [19]) using the "vegan" package (Oksanen et al. [20]) and "BiodiversityR" package (Kindt and Coe [21]) in R. Ordination plots were generated for cultivar values and a 95\% confidence interval was fitted.
Two-dimensional hierarchical cluster analysis (HCA) was performed with the hclust function in package stat in $\mathrm{R}$ software version 3.1.3. Random forest analysis was performed using the random forest package (Liaw and Wiener [22]).

\section{Results and Discussion}

3.1. Apple Cultivars Are Discriminated by the Volatile Organic Compound Profile. Based on a comparison with custom libraries derived from NIST17, a total of 40 compounds were putatively identified in the aroma profile of the four cultivars in this study using this VOC collection and analysis method. These are composed of several classes of organic compounds: esters were the largest group (30), of which 11 were acetate esters and 19 nonacetate esters, followed by ketones 


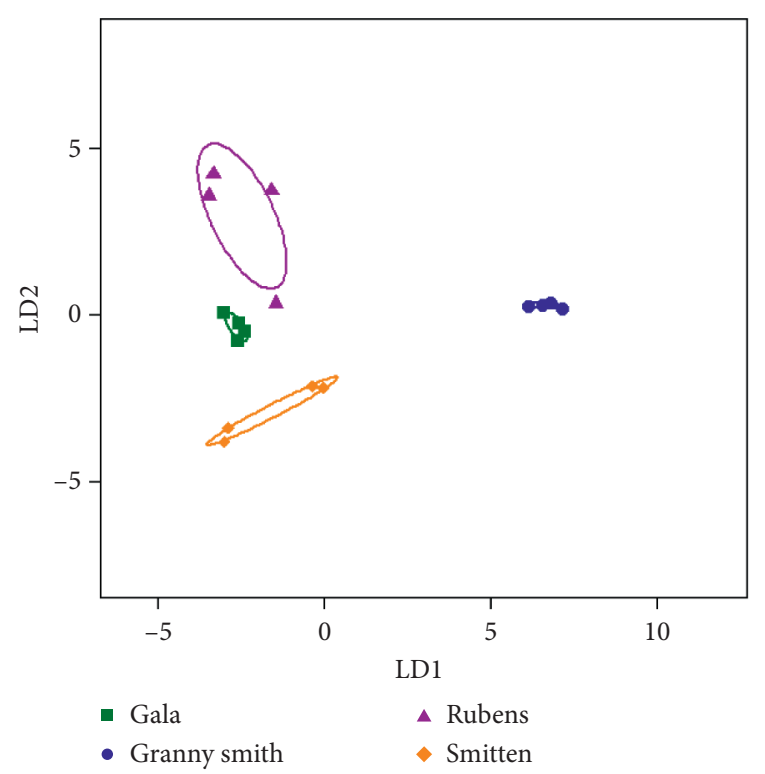

FIGURE 1: Canonical analysis of principal coordinates based on all apple VOCs using TD-GCxGC-TOF-MS: a CAP model was produced from apple samples of four cultivars. The plot uses the first two linear discriminants (LD); each ellipse represents the $95 \%$ confidence interval. Percentage of correct classification of $93.75 \%$ $(P<0.01, n=4)$. LD1 vs. LD2 accounted for $90.1 \%$ of the total variation within data.

(3), and the other compounds were one for each of the following classes: alcohol, aldehyde, alkene, benzenoid VOC, carboxylic acid, terpene, and sesquiterpenoid (Table 1).

Twelve of the compounds detected were identified and quantified as apple odorant volatile compounds in previous studies $[12,13]$. Each one has been detected and described as follows: n-propyl acetate, fruity, floral; isobutyl acetate, pear, apple; acetic acid; acetic acid, butyl ester, fruity; 1-butanol, 2methyl-, acetate, fruity, apple; n-hexanal, green; propanoic acid, butyl ester, red fruit, strawberry; acetic acid, pentyl ester, fruity, banana; butanoic acid, butyl ester, rotten fruit; acetic acid, hexyl ester, sweets, pear; butanoic acid, 2methylbutyl ester, fruity, apple; camphor, camphor, pine (Table 1). In particular, eight of these compounds are part of the group of principal odorant compounds detected by $\geq 75 \%$ of assessors in aroma extracts of Golden Delicious, Fuji, and Braeburn apples [13]. A further review of the list of compounds detected from the cultivars has enabled the identification of four other compounds associated with apple flavour, namely, butanoic acid, 2-methyl-, pentyl ester; butanoic acid, 2-methyl-, hexyl ester; propanoic acid, 2methyl-, hexyl ester; butanoic acid, hexyl ester (Table 1) (http://www.thegoodscentscompany.com [23]). Of the forty compounds in the list, eight were not previously identified in apples (given in italics in Table 1).

The overall pattern of relative abundance of VOC compounds (abundance of each VOC as a proportion of the total profile abundance) differed significantly amongst cultivars (permutational multivariate analysis of variance, PerMANOVA, $P<0.0001)$. Overall, PerMANOVA accounted for $80 \%$ of the variation of the data set. Linear discrimination
(LD) plot produced from CAP with a percentage of correct classification of $93.75 \%(P<0.01)$ show separation of the four cultivars using a $95 \%$ confidence interval (Figure 1). Granny Smith (often used in salads and cookery recipes) is separated from Gala, Rubens, and Smitten (mainly used for eating) on LD1. Furthermore Gala, Rubens, and Smitten are separated on LD2.

Random forest was applied to the data in order to find a minimum set of variables (VOCs in this case) that could successfully discriminate between cultivars. The top fifteen compounds ranked by the mean decrease in classification accuracy (Figure 2) resulted in retaining an excellent discrimination between cultivars based on CAP (LD1 vs. LD2 $=100 \%, P<0.001$ ) (Figure 3 ).

Table 2 illustrates significant differences between cultivars for each of the fifteen compounds (ANOVA with post hoc Tukey's HSD test). These include VOCs that are significantly positively correlated with each cultivar (Figure 2 and Table 2), suggesting they could represent good candidates as markers to distinguish between cultivars. In particular, acetic acid, hexyl ester; hexyl tiglate and estragole correlate with Gala; $\gamma$-himachalene correlates with Granny Smith; butanoic acid, butyl ester; butanoic acid, hexyl ester; butyl 2-methylbutanoate; hexanoic acid, pentyl ester; propanoic acid, hexyl ester correlate with Rubens, and 1butanol, 2-methyl-, acetate and isobutyl acetate significantly positively correlated with the apple cultivar Smitten.

\subsection{Correlations between Consumer Appreciation and Aroma} Signatures. Two-dimensional HCA was used to allow trends across samples, VOCs, and sensory evaluation (Figure 4), for example, 1-butanol, 2-methyl-, acetate (C6), which is shown to be the top discriminator signature for the cultivars studied (Figure 2) clusters with taste/flavour and fruitiness (Figure 4). These variable changes in parallel are high in Smitten and very low in Granny Smith, the latter being the least appreciated cultivar (Figure 4). These results are in accordance with reported findings where 1-butanol, 2-methyl-, acetate (C6) is described as one of the fifteen POC detected in Golden Delicious, Fuji, and Braeburn apple cultivars [13].

Another discriminator variable identified through random forest is isobutyl acetate (C52) (Figure 2). This compound is positively associated with the perception of sweetness and overall flavour (Figure 4). Three compounds, acetic acid, hexyl ester (C20); acetic acid, pentyl ester (C49); acetic acid, butyl ester (C18), are associated with the trait of aroma/smell. This result confirms previous findings, where the previously mentioned compounds were reported in the fifteen POC detected by $\geq 75 \%$ of panellists in aroma extracts of Golden Delicious, Fuji, and Braeburn apples [13].

The association between 4-hexen-1-ol, acetate (C16), texture/consistency, and crispiness could also be of interest for the identification of relevant apple characteristic features. Furthermore 2-methylbut-2-en-1-yl acetate (C13) was found to correlate with another two very important traits, in the choice of apple, namely, juiciness and acidity (Figure 3). To the best of our knowledge, this is the first time these compounds are detected in the analysis of apple aroma. 


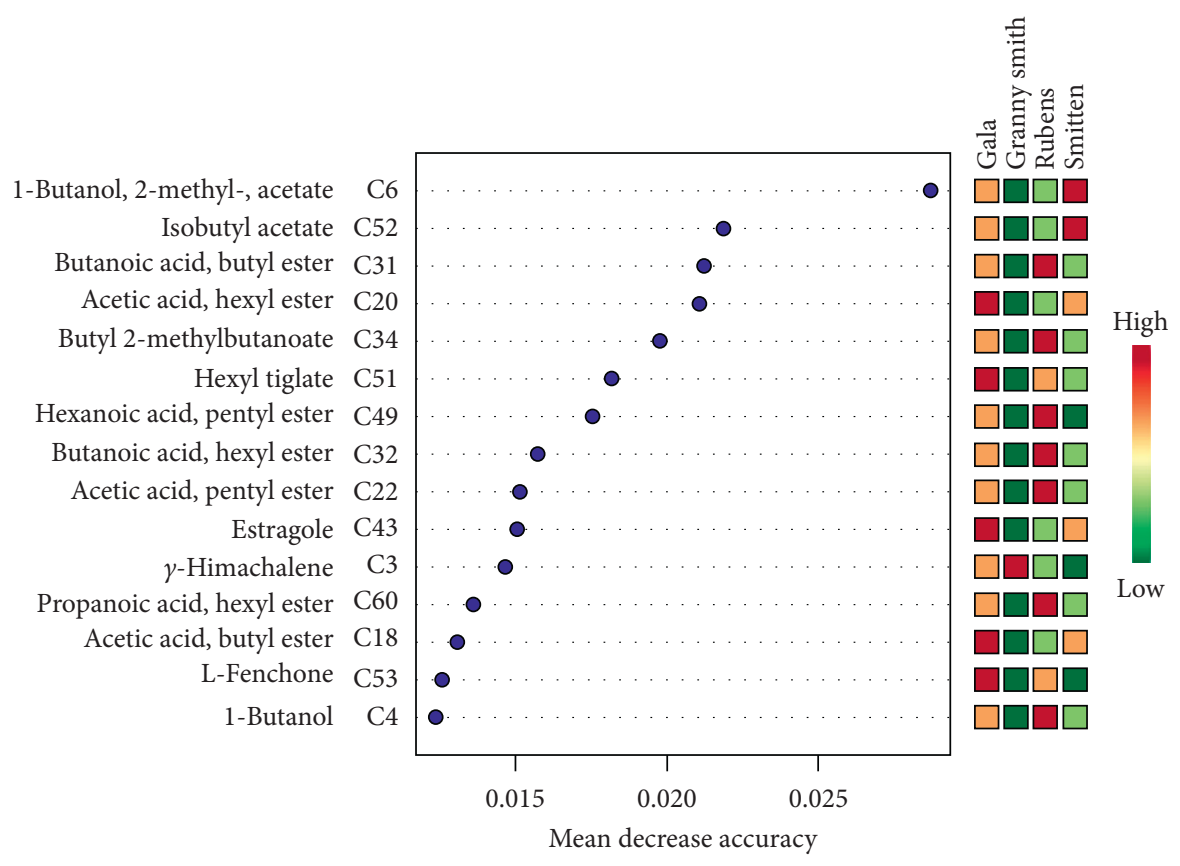

FIGURE 2: Representations of variety specific volatile signatures. Significant features identified by random forest within the full data set of apple cultivars. The features are ranked by the mean decrease in classification accuracy when they are permuted.

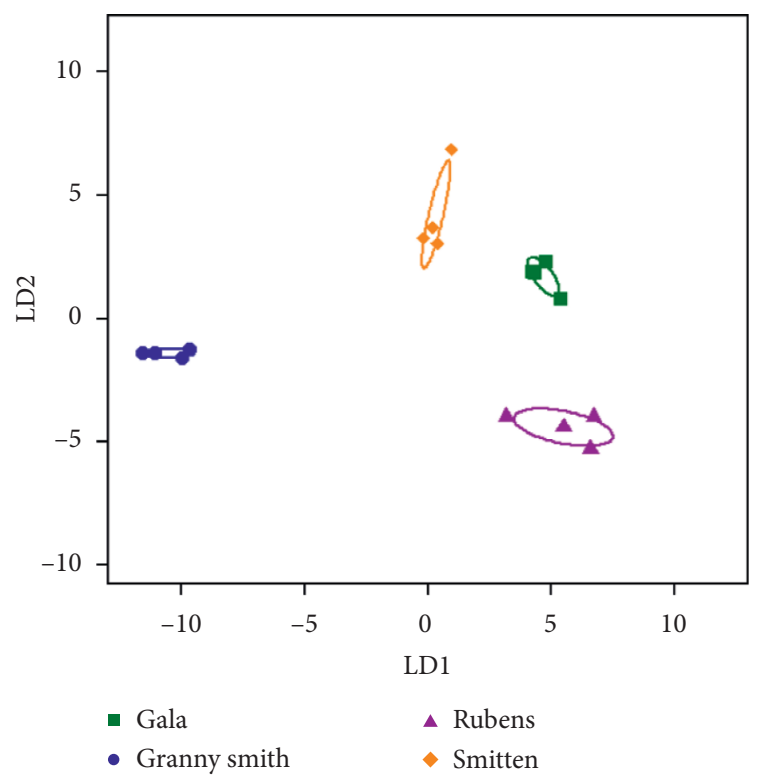

Figure 3: Canonical analysis of principal coordinates based on top 15 VOCs ranked by the mean decrease in classification accuracy: a CAP model was produced from apple samples of four cultivars. The plot uses the first two linear discriminants (LD); each ellipses represents the $95 \%$ confidence interval. Percentage of correct classification of $100 \%(P<0.001, n=4)$. LD1 vs. LD2 accounted for $100 \%$ of the total variation within data.

Furthermore, the association of such important traits such as texture, crispiness juiciness and acidity identified through HCA of VOC and sensorial attributes could be important for growers as well as producers interested in apple taste for consumers.
TABLE 2: Means of percentage relative abundance with standard error and significant differences $(P \leq 0.05)$ of top 15 volatile compounds detected in the headspace of apple cultivars. Values expressed as percentage of the total volatiles detected per sample.

\begin{tabular}{lcccc}
\hline \multirow{2}{*}{ VOCs } & \multicolumn{4}{c}{ Cultivar } \\
& Gala & Granny smith & Rubens & Smitten \\
\hline C3 & $4.9 \pm 0.5^{\mathrm{a}}$ & $89.4 \pm 4.4^{\mathrm{b}}$ & $7.1 \pm 0.5^{\mathrm{a}}$ & $20.5 \pm 1.3^{\mathrm{a}}$ \\
C4 & $0.04 \pm 0.00^{\mathrm{a}}$ & $\mathrm{nd}^{\mathrm{b}}$ & $0.08 \pm 0.0^{\mathrm{a}}$ & $\mathrm{nd}^{\mathrm{b}}$ \\
C6 & $22.2 \pm 1.3^{\mathrm{a}}$ & $\mathrm{nd}^{\mathrm{b}}$ & $10.0 \pm 2.8^{\mathrm{c}}$ & $32.0 \pm 6.2^{\mathrm{d}}$ \\
C18 & $12.4 \pm 4.0^{\mathrm{a}}$ & $\mathrm{nd}^{\mathrm{b}}$ & $11.2 \pm 6.0^{\mathrm{a}}$ & $6.9 \pm 1.5^{\mathrm{a}}$ \\
C20 & $32.2 \pm 1.4^{\mathrm{a}}$ & $3.9 \pm 2^{\mathrm{b}}$ & $18.0 \pm 0.7^{\mathrm{c}}$ & $19.1 \pm 2.1^{\mathrm{c}}$ \\
C22 & $2.6 \pm 0.1^{\mathrm{a}}$ & $\mathrm{nd}^{\mathrm{b}}$ & $2.4 \pm 0.5^{\mathrm{a}}$ & $2.5 \pm 0.3^{\mathrm{a}}$ \\
C31 & $0.7 \pm 0.1^{\mathrm{a}}$ & $\mathrm{nd}^{\mathrm{b}}$ & $4.1 \pm 0.9^{\mathrm{c}}$ & $007.1 \pm 0.00^{\mathrm{b}}$ \\
C32 & $2.0 \pm 0.25^{\mathrm{a}}$ & $0.1 \pm 0.01^{\mathrm{b}}$ & $11.1 \pm 3.0^{\mathrm{c}}$ & $0.3 \pm 0.00^{\mathrm{b}}$ \\
C34 & $0.2 \pm 1.8^{\mathrm{a}}$ & $\mathrm{nd}^{\mathrm{a}}$ & $2.4 \pm 0.6^{\mathrm{b}}$ & $0.06 \pm 0.00^{\mathrm{a}}$ \\
C43 & $2.9 \pm 0.3^{\mathrm{a}}$ & $\mathrm{nd}^{\mathrm{b}}$ & $0.1 \pm 0.0 \mathrm{~b}^{\mathrm{c}}$ & $0.4 \pm 0.1^{\mathrm{c}}$ \\
C49 & $0.03 \pm 0.00^{\mathrm{a}}$ & $\mathrm{nd}^{\mathrm{a}}$ & $0.6 \pm 0.03^{\mathrm{b}}$ & $\mathrm{nd}^{\mathrm{a}}$ \\
C51 & $0.2 \pm 0.00^{\mathrm{a}}$ & $\mathrm{nd}^{\mathrm{b}}$ & $0.07 \pm 0.0^{\mathrm{c}}$ & $0.03 \pm 0.00^{\mathrm{c}}$ \\
C52 & $0.2 \pm 0.00^{\mathrm{a}}$ & $\mathrm{nd}^{\mathrm{a}}$ & $0.2 \pm 0.00^{\mathrm{a}}$ & $1.3 \pm 0.5^{\mathrm{b}}$ \\
C53 & $0.1 \pm 0.00^{\mathrm{a}}$ & $\mathrm{nd}^{\mathrm{b}}$ & $\mathrm{nd}^{\mathrm{b}}$ & $\mathrm{nd}^{\mathrm{b}}$ \\
C60 & $0.2 \pm 0.00^{\mathrm{a}}$ & $\mathrm{nd}^{\mathrm{a}}$ & $3.2 \pm 0.8^{\mathrm{b}}$ & $0.03 \pm 0.00^{\mathrm{a}}$ \\
\hline
\end{tabular}

$\mathrm{nd}=$ not detected. Superscript letters in the same row indicate differing levels of significance for each respective cultivar (ANOVA Tukey's HSD test; $P \leq 0.05)$.

An interesting cluster is noted in the HCA. Three compounds, n-hexanal (C11), acetic acid (C17), and $\gamma$-himachalene (C3), are positively correlated with Granny Smith apple cultivar. However, these compounds do not show any correlation with any sensory attribute. Granny Smith is the least appreciated cultivar and only five analytes could be detected in its flavour bouquet. The aldehyde n-hexanal has been reported before as one of the fifteen POC detected by panellists in the aroma extract of apple cultivars 


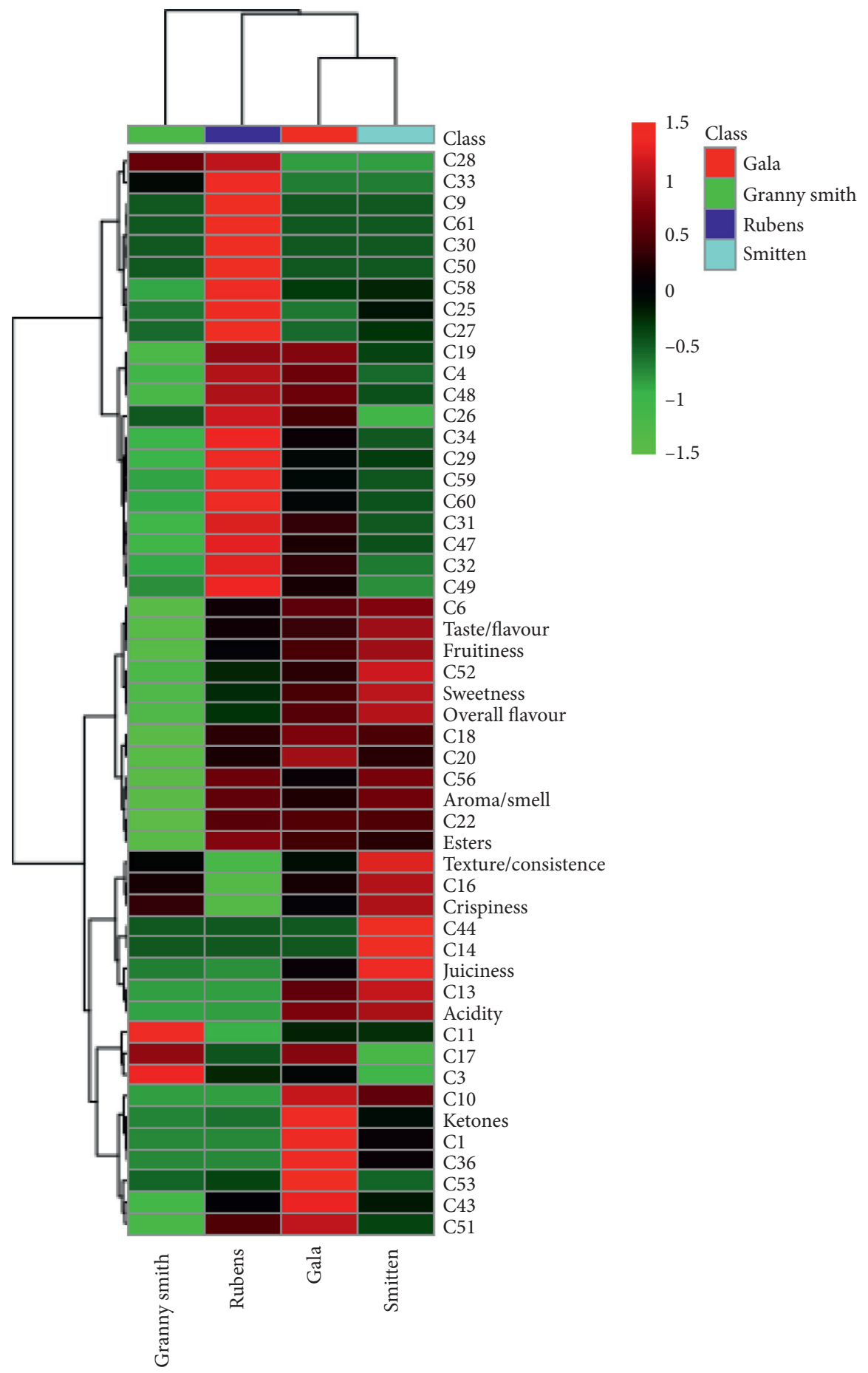

FIgURE 4: Two-way hierarchical clustering heatmap of cultivars for volatile compounds (represented as codes; full VOC name can be found in Table 1) and sensorial attributes. Green indicates a low content, black, intermediate, and red, high, for each character.

[13], while, to the best of our knowledge, $\gamma$-himachalane has not been reported before as a possible candidate for the characterization of apple flavour and the flavours so far associated to it are leafy, anise, spice, and fungi $[23,24]$.

\section{Conclusion}

We demonstrate that the implemented methodology for the collection and analysis of VOCs is robust enough to show that there are significant differences amongst cultivars in the relative abundance of volatile profiles they produce. The sampling technology presented here could also be used by the food supply industry as part of routine quality control, reducing costs, and eliminating waste due to batches of inferior product.

The discriminatory features generated by random forest could confer important information to growers, producers, 
and stakeholders when choosing a cultivar to commercialise. On the other hand, consumers could have receptors for the specific compounds present in some cultivars that give clues for health and nutritional value ultimately dictating their choice. Consequently, variables identified in this study can provide candidate VOCs for further behavioural testing on humans to determine the specific signals employed by them to buy the favourite cultivar. Furthermore, the sensory correlations indicate that that the compounds reported above could be used as objective markers for the consumer appreciation of fresh apples, enabling optimum conditions for processing and storage of individual cultivars to be identified without recourse to expensive sensory panels in every case.

\section{Data Availability}

The data used to support the finding of this research are available from the corresponding author upon request.

\section{Conflicts of Interest}

The authors declare no conflicts of interest.

\section{Acknowledgments}

This work was supported by Fondazione CON IL SUD, call Brain2South, as part of the FRUITY collaborative project (2015-0245).

\section{References}

[1] S. A. Goff and H. J. Klee, "Plant volatile compounds: sensory cues for health and nutritional value?" Science, vol. 311, no. 5762, pp. 815-819, 2006.

[2] V. J. L. Ting, A. Romano, P. Silcock et al., "Apple flavor: linking sensory perception to volatile release and textural properties," Journal of Sensory Studies, vol. 30, no. 3, pp. 195-210, 2015.

[3] M. L. Corollaro, I. Endrizzi, A. Bertolini et al., "Sensory profiling of apple: methodological aspects, cultivar characterisation and postharvest changes," Postharvest Biology and Technology, vol. 77, pp. 111-120, 2013.

[4] L. Seppä, J. Railio, K. Vehkalahti, R. Tahvonen, and H. Tuorila, "Hedonic responses and individual definitions of an ideal apple as predictors of choice," Journal of Sensory Studies, vol. 28, no. 5, pp. 346-357, 2013.

[5] B. Daillant-Spinnler, H. J. H. Macfie, P. K. Beyts, and D. Hedderley, "Relationships between perceived sensory properties and major preference directions of 12 varieties of apples from the Southern hemisphere," Food Quality and Preference, vol. 7, no. 2, pp. 113-126, 1996.

[6] F. R. Harker, F. A. Gunson, and S. R. Jaeger, "The case for fruit quality: an interpretive review of consumer attitudes, and preferences for apples," Postharvest Biology and Technology, vol. 28, no. 3, pp. 333-347, 2003.

[7] E. M. Yahia, "Apple flavour," Horticultural Reviews, pp. 197-234, John Wiley \& Sons, New York, NY, USA, 1994.

[8] M. Espino-Díaz, D. R. Sepúlveda, G. González-Aguilar, and G. I. Olivas, "Biochemistry of apple aroma: a review," Food Technology and Biotechnology, vol. 54, no. 4, pp. 375-394, 2016.
[9] E. Aprea, M. L. Corollaro, E. Betta et al., "Sensory and instrumental profiling of 18 apple cultivars to investigate the relation between perceived quality and odour and flavour," Food Research International, vol. 49, no. 2, pp. 677-686, 2012.

[10] H. Young, J. M. Gilbert, S. H. Murray, and R. D. Ball, "Causal effects of aroma compounds on royal Gala apple flavours," Journal of the Science of Food and Agriculture, vol. 71, no. 3, pp. 329-336, 1996.

[11] M. L. Lopez, M. T. Lavilla, I. Recasens, J. Graell, and M. Vendrell, "Changes in aroma quality of ?Golden Delicious? apples after storage at different oxygen and carbon dioxide concentrations," Journal of the Science of Food and Agriculture, vol. 80, no. 3, pp. 311-324, 2000.

[12] E. Fuhrmann and W. Grosch, "Character impact odorants of the apple cultivars Elstar and Cox Orange," Nahrung/Food, vol. 46, no. 3, pp. 187-193, 2002.

[13] E. Mehinagic, G. Royer, R. Symoneaux, F. Jourjon, and C. Prost, "Characterization of odor-active volatiles in apples: influence of cultivars and maturity stage," Journal of Agricultural and Food Chemistry, vol. 54, no. 7, pp. 2678-2687, 2006.

[14] A. L. Amaro, N. D. Spadafora, M. J. Pereira et al., "Multitrait analysis of fresh-cut cantaloupe melon enables discrimination between storage times and temperatures and identifies potential markers for quality assessments," Food Chem.vol. 241, pp. 222-231, 2018.

[15] L. Bell, N. D. Spadafora, C. T. Müller, C. Wagstaff, and H. J. Rogers, "Use of TD-GC-TOF-MS to assess volatile composition during post-harvest storage in seven accessions of rocket salad (Eruca sativa)," Food Chemistry, vol. 194, pp. 626-636, 2016.

[16] N. D. Spadafora, G. Cocetta, M. Cavaiuolo et al., "A complex interaction between pre-harvest and post-harvest factors determines fresh-cut melon quality and aroma," Scientific Reports, vol. 9, no. 1, pp. 1-15, 2019.

[17] J. M. Murray, C. M. Delahunty, and I. A. Baxter, "Descriptive sensory analysis: past, present and future," Food Research International, vol. 34, no. 6, pp. 461-471, 2001.

[18] L. M. Bartoshuk, V. B. Duffy, K. Fast, B. G. Green, J. Prutkin, and D. J. Snyder, "Labeled scales (e.g., category, Likert, VAS) and invalid across-group comparisons: what we have learned from genetic variation in taste," Food Quality and Preference, vol. 14, no. 2, pp. 125-138, 2003.

[19] M. J. Anderson and T. J. Willis, "Canonical Analysis of Principal coordinates: a useful method of constrained ordination for ecology," Ecology, vol. 84, no. 2, pp. 511-525, 2003.

[20] J. Oksanen, F. Guillaume Blanchet, R. Kindt et al., "Vegan: Community Ecology Package," R Package Version 2.0-8," 2013, https://cran.r-project.org/web/packages/vegan/index.html.

[21] R. Kindt and R. Coe, "Tree diversity analysis," in A Manual And Software for Common Statistical Methods for Ecological and Biodiversity Studies, World Agroforestry Centre (ICRAF), Nairobi, Kenya, 2005.

[22] A. Liaw and M. Wiener, "Classification and regression by random- Forest," Rnews, vol. 2, pp. 18-22, 2002.

[23] http://www.thegoodscentscompany.com.

[24] J. O'Leary, Multi-Dimensional Mycelia Interactions, Ph. D. thesis, Cardiff University, Cardiff, UK, 2018, http://orca.cf.ac. uk/111801/1/2018O\%27LearyJphd.pd. 